\title{
Contents, Vol. 39, Supplement 1, 1980
}

\section{Foreword}

Ketotifen, an Anti-Allergic Drug. Pharmacological Figures and Clinical Experience von Wichert, P. (Hamburg-Eppendorf) ...

Ketotifen versus Sodium Cromoglycate in the Therapy of Allergic (Extrinsic) Bronchial Asthma Szczeklik, A.; Czerniawska-Mysik, G.; Adamek-Guzik, T., Woloszynski, J., and Koterba, A. (Cracow)

Ketotifen in Bronchial Asthma

Morris, M. J. and Lane, D. J. (Oxford)

The Protective Effect of Ketotifen in Bronchial Asthma

Stangl, B.; Furlan, J.; Ustar, M., and Janeziס, A. (Golnik)

Double-Blind Study Comparing Ketotifen and

DSCG in Adolescent Asthmatics

Lamarre, A.; Vincke, P.; Lapierre, J. G., and

Ackermans, F. (Montreal)

Oral Prophylaxis of Bronchial Asthma in Chil

dren

Spicak, V. (Prague-Motol)

Comparison of Ketotifen, Dísodium Cromo-

V glycate and Placebo in the Treatment of Adult

Patients with Extrinsic Asthma Mattson, K.; Poppius, H.; Ahonen, A.; Haahtela, T.; Hurme, R.; Maasilta, P.; Mu-

ittari, A., and Venho, K. (Helsinki) 20

Inhibition of Idiosyncratic Reactions to Aspirin

1 by Ketotifen

Szczeklik, A.; Czerniawska-Mysik, G.; Ser-

wonska, M., and Kuklinski, P. (Cracow)... 24

Use of Anterior Rhinometry in Nasal Provoca

tion Challenges with Allergen and Evaluation

of the Effects of Ketotifen, Clemastine and

3 Sodium Cromoglycate on these Responses

Phillips, M. J.; Oilier, S., and Davies,R. J.

10 (London) 26

Protective Effect of Various Drugs in Preventing an Acetylcholine-Induced Bronchoconstric-tion 12 Kaik, G. and Kaik, B. (Vienna) 32

Effect of Ketotifen in Some Immunological Animal Models

Borel,J.F. (Basel) 38 
16 Effects of Cyproheptadine, Ketotifen and So dium Nitroprusside on Mechanical Activity and Calcium Uptake in Guinea Pig Taenia 18 coli in vitro

Lowe, D. A. and Richardson, B. P. (Basel).. 44 